\title{
Ahead to the Past? Responsibility to Protect and the Global System
}

Carlo Focarelli ${ }^{1}$

DOI: $10.21827 / 5 \mathrm{a} 86 \mathrm{a} 6 \mathrm{dbb} 211 \mathrm{~b}$

\begin{abstract}
The Responsibility to Protect (RtoP) is premised on the idea that States protect their peoples in return for obedience. Effective protection, however, is dependent on States having enough power to make themselves obeyed by transgressors. Such power is limited at a time where freedom and rights prevail as catchwords, but where 'duty' and 'responsibility' are shunned. Citizens of a State performing badly on RtoP standards may want to substitute their failing state with non-state actors believed to offer adequate protection, promising maximum freedom at a lower cost. This, however, will amount to modern-day slavery. As such, if the RtoP doctrine is to have meaning in the future, it must be accompanied by responsible States, which in turn are comprised of responsible peoples.
\end{abstract}

\section{Introduction}

The Responsibility to Protect (Top) doctrine is based on the assumption that the state is to remain at the heart of world order. ${ }^{2}$ It is true that the doctrine implies a weakening of state sovereignty concomitant with the process of globalisation and greater possibility of interference in the internal affairs of states than in the past. What is weakened, however, is the individual state, i.e. this or that state which behaves irresponsibly, not the state as such, nor the global system of states. RtoP presupposes the existence of states at the core of the system. It requires states to behave responsibly towards their own citizens and calls for measures to be taken by states, possibly in cooperation with international organisations and other non-state actors.

A question that is rarely posed when dealing with RtoP is whether and to what extent RtoP can work in a world in which states appear less and less capable of providing people with protection. The global economy, in particular, is often said to undermine the current ability of states to provide protection from unemployment, state insolvency, hunger, and other economic macro-variables affecting people's daily lives. In these conditions the appeal of RtoP to the responsibility of governments, either to protect their own citizens or to intervene elsewhere to assist people in need, risks sounding like the last cry for a better boat while the boat is irremediably sinking.

I propose that RtoP is seen from this global perspective. For sake of brevity, the following observations will take nearly all RtoP details and literature for granted and will not engage with the many views surrounding the doctrine. The focus is on whether RtoP makes sense in a world of states which appear increasingly unable to afford it and on the possible consequences that this state of affairs may have for the protection of people in the future.

\footnotetext{
${ }^{1}$ Professor of International Law, University of Perugia and LUISS Guido Carli University of Rome, Italy.

${ }^{2}$ For recent general treatments of RtoP, see in particular Orford, A., International Authority and the Responsibility to Protect, Cambridge University Press, Cambridge, 2011; Genser, J. and Cotler, I. (eds.), The Responsibility to Protect: The Promise of Stopping Mass Atrocities in Our Time, Oxford University Press, Oxford, 2012.
} 


\section{Legal Bugs in the RtoP Doctrine}

Far too many difficulties surround RtoP as a legal standard (as opposed to a banner for political struggle): (a) is there an 'emerging norm', or hopefully a rule or a set of rules already in effect, in international law authorising (if not imposing) RtoP? (b) If so, to which situations does it apply exactly? (c) What is its content? (d) Which otherwise unlawful measures does it allow to take? (e) Who exactly is allowed to take such measures? (f) Is RtoP doctrine really necessary to support the existence of a rule or rules leading to such legal results?

All of the above questions are far from having received a convincing answer. First, no RtoP 'emerging norm' (neither customary, nor natural) exists, let alone a rule or set of rules already in force having the effect of modifying legal outcomes on the sole ground of RtoP as a general doctrine. RtoP per se thus neither authorises nor imposes any otherwise unlawful measure, nor does it make mandatory an exhortatory measure. Even as a 'guide to behaviour', as sometimes presented, it lacks clarity.

Secondly, attempts have been made to 'apply' RtoP to a variety of situations going well beyond those endorsed by the UN General Assembly in $2005,{ }^{3}$ including terrorist attacks from abroad $^{4}$ and natural disasters, ${ }^{5}$ but with little success.

Thirdly, RtoP presupposes a duty that states have to protect their own citizens, but it focuses on the measures that may be adopted to respond to the breach of such a duty. It is also unclear what RtoP means when referring to 'prevention' and 'protection'. It seems that the yardstick is what is 'in the power' of the state concerned. But this varies markedly with states and with the moment considered even within one given state. Nor is it clear who is entitled to assess the 'power' of any single state in order to see it as compliant with the prevention standard for RtoP response purposes. Even more obscure is the question of who should shoulder the costs of rebuilding (as resulting from the RtoP third-pillar duty to rebuild).

Fourthly, the measures envisaged in the abstract to 'implement' RtoP are extremely diverse. ${ }^{6}$ Some of them may be adopted without any need to appeal to RtoP (such as

\footnotetext{
${ }^{3}$ GA Resolution 1 (60), 24 October 2005, "World Summit Outcome" document, UN Doc A/RES/60/1, limiting the hypotheses under which states are 'prepared' to react to genocide, war crimes, ethnic cleansing, and crimes against humanity (par. 138-139). See also UNSG Report of 12 January 2009, "Implementing the Responsibility to Protect", UN Doc A/63/677, pointing out that RtoP applies only to 'genocide, war crimes, ethnic cleansing and crimes against humanity', and should not extend to 'other calamities, such as HIV/AIDS, climate change or the response to natural disasters' (par. 10(b)). See, for more recent discussions at the the UN Security Council, UN Doc S/PV.6650 (Resumption 1), 9 November 2011, and the statements made at the UN General Assembly by Belgium, Benin, Brazil, Costa Rica, Cuba, Estonia, U; Ghana, Holy See, Italy, Liechtenstein, Luxembourg, Macedonia, the Netherlands, Nicaragua, Norway, Paraguay, Sweden, Syria, Zimbabwe at $<$ http://gadebate.un.org>, accessed 20 April 2012.

${ }^{4}$ Feinstein, L. and Slaughter, A., "A Duty to Prevent", Foreign Affairs, 83 (2004) 136-150. The attempt to apply RtoP to security threats, especially terrorism, is today relatively frequent in legal doctrine and also the practice of justifying the military response as self-defence against non-state actors. In 2008, Israel observed that states have a duty 'to ensure that international [terrorist] attack against civilians' in other states are not launched from their territory, hence a duty of the targeted states 'to protect civilians', cf. UN Doc S/PV.5898 (Resumption 1), 27 May 2008,7 , assuming that military action by the targeted state is permissible for the 'protection' of its own citizens as distinct from the citizens of the state which is unable or unwilling to control its territory from which attacks have been launched.

${ }^{5}$ Saechao, T. R., "Natural Disasters and the Responsibility to Protect: From Chaos to Clarity" BJIL 32 (2007) 663-707; Focarelli, C., "Duty to Protect in Cases of Natural Disasters", in: Wolfrum, R. (ed.), Max Planck Encyclopedia of Public International Law, March 2010, available online at <http://www.mpepil.com/home> (accessed 26 March 2012).

${ }^{6}$ For an interesting account of possible 'RtoP measures', without however showing the difference RtoP makes in legal terms in order for them to be lawful (when otherwise unlawful) or mandatory (when otherwise exhortatory), but insisting on the political interest for the United States to uphold the doctrine (see also Infra note 8), see Genocide Prevention Task Force, Preventing Genocide: A Blueprint for U.S. Policymakers, released on 8 December 2008, available online at <http://www.ushmm.org/genocide/taskforce/report.php> (accessed 26 March 2012),
} 
'retorsions'). Others may become mandatory by virtue of RtoP, while otherwise exhortatory, but only provided that specific (i.e. independent of mere reference to the 'RtoP label') supporting evidence is given. Still others may become lawful, where otherwise unlawful, but this must also be specifically proven. True, an otherwise exhortatory measure may become mandatory when imposed by the Security Council under Article 41 UN Charter relying on RtoP based on a 'threat to the peace' under Article $39,{ }^{7}$ but then Article 41 is the source of the obligation, not RtoP per se.

Fifthly, a wide range of potential actors who may take up RtoP have been proposed, ranging from the United Nations to states acting unilaterally, but perhaps the only certainty is the lawfulness of (otherwise unlawful) action taken under the authorisation of the UN Security Council under Chapter VII, which again depends on the Charter rather than on RtoP per se. Finally, faced with all such uncertainties, one is led to argue that, however politically meaningful and impacting in terms of the law to be brought about in the future, RtoP simply makes no legal difference in respect to the law as it now stands.

One must also bear in mind that RtoP, despite its generally welcome reception, suffers a lack of credibility, and hence of feasibility, even from the perspective of its possible future materialisation as a legal rule. It appears to be one-sided and to rest on the willingness of the stronger states (which set the standards of response) to take action against weaker states. While today there certainly are common standards concerning certain gross violations of human rights, such as genocide, no common RtoP standard exists as to the measures that are justified in response thereto. For example, nowhere does the 1948 Genocide Convention envisage military intervention as a response to its violations, although it definitely states when a certain conduct constitutes genocide and which remedies are allowed (not expressly including military intervention) to respond to its violation. So, while it may well be worth fighting for a legal rule inspired by RtoP to emerge in the future, it still remains to determine the content thereof, content which presents reasonable prospects to make lawful otherwise unlawful conduct or at least to make mandatory an otherwise exhortatory conduct. For this to occur, RtoP needs to be stated as a tool credibly capable of working in a two-way manner, not simply by Western states (left free to act only when it is in their interest to do so) against any other. ${ }^{8}$

For a general 'doctrine' to become a legal rule, a standard of general application expected as such by any state to be observed by any other state when identical conditions are met, whatever the state, must exist and must be accepted. But it is difficult to see how this can be the case if each state endorses RtoP as a tool for foreign policy gains, possibly accompanied by moral or humanitarian considerations (when these are felt to contribute to the state's own values and interests). One may sympathise with the RtoP policy of one or another state, but this is not enough for a rule to emerge. This point is often well hidden behind the appeal to morality and human dignity, but it is crucial if one is genuinely interested in a legal rule embodying RtoP, or more accurately specific legal consequences thereof, rather than in foreign policy gains or political struggle. RtoP as a means to an end available to any state for its own ends may work as a banner for struggle but can hardly lead to a universally shared legal rule of general application.

limiting itself to define RtoP as "an important tool for moral suasion" (98-99) designed to "provide the legitimate basis for overriding national sovereignty" (58). RtoP has been generically endorsed by US President Barack Obama, without looking into the surrounding legal issues, The White House, National Security Strategy, 26 May 2010, available online at <http://whitehouse.gov/sites/default/files/rss_viewer/national_security_strategy.pdf>, 22 (accessed 26 March 2012).

${ }^{7}$ This point is discussed below, par. 4.

${ }^{8}$ In this sense the Preventing Genocide Report (Supra note 5) is of doubtful import, rooted as it is (for understandable reasons, to be sure) in the notion that RtoP can be used to 'enhance American interests and values'. The report constantly and candidly oscillates between 'universal values' and 'national interests', between humanitarian considerations and security exigencies, suggesting that the latter absorb the former insofar as the former are basically to be pursued to enhance the latter. 
Clearly, while communicative strategies seem to dominate the debate, a global sense of equality and trust should be ensured as a general presupposition of RtoP for it to be legally successful without translating into yet another imperialistic diktat in disguise. ${ }^{9}$

\section{RtoP Between States}

One of the key tenets of RtoP is that, in cases where a state proves unable or unwilling to protect its own citizens, it is for the international community as a whole to take adequate measures to protect the victims. By the 'international community as a whole' is meant a variety of state and non-state actors. However, it is states that are ultimately supposed to intervene, possibly under the mandate of the United Nations and pressure from non-state actors and 'global civil society'. Realities show that: (a) most states are simply unable to meet the standards of RtoP and (b) few if any states are as altruistic, willing and able as expected, to react, let alone rebuild, in terms of RtoP. ${ }^{10}$

The theoretical notion that in a globalised world what occurs within each state reverberates through any other state and the entire global community is one thing, the law as it actually stands is quite another. One should certainly struggle for a better law, but the law which is worth struggling for is for the future. We definitely need to struggle for a better law for the future, but we also need to identify the law as it stands at present since it is now that the law applies and there is no certainty that the struggle for a better law will ever be successful. States are anything but convinced that RtoP is a legal rule, binding on their behaviour in support of people in need in another state. They often praise RtoP, but their praise may simply suggest that they value it for political mediation, not necessarily as a legally binding rule.

In particular, Western states are anything but inclined towards RtoP as a legally mandatory rule; they are simply 'prepared' to use RtoP on a case-by-case basis, which in practice means when there is a gain in sight. Non-western states, for their part, fear RtoP as a neo-colonialist device, not much different from many others of the past; true, they also are 'prepared' to endorse the doctrine, but provided that a number of safeguards are set out. Unfortunately, the (quite reasonable) safeguards they request, beginning with a prohibition of selectivity, is overtly unacceptable to Western states, which (no less reasonably) can hardly afford to use their resources exclusively for the benefit of others. ${ }^{11}$

The notion underlying RtoP that sovereignty is for the protection of the ruled and not for the privilege of the rulers is as old as the state. The early theorists of the state insisted that the state is in the service of the ruled and many have endorsed both the right of resistance and a right (if not a duty) of other states against a tyrant within the then Christian family of nations. ${ }^{12}$ In this respect RtoP presupposes and needs the so-called 'Westphalian system'. The rhetoric that RtoP is a breakthrough because it places the individual at the heart of the global system is greatly exaggerated. RtoP presupposes a world made up of states working as tools to provide people with protection. What has changed in recent times is the quality and quantity of international obligations placed on states and how they have to treat any individual within their jurisdiction.

\footnotetext{
${ }^{9}$ Bricmont, J., "A More Just World and the Responsibility to Protect", Interactive Thematic Dialogue on the Responsibility to Protect, 23 July 2009, United Nations, New York, available online at <http://www.un.org/ga/president/63/interactive/protect/jean.pdf>, noting that "If we want some version of R2P to work in the future, we need first to build a relationship of equality and trust" (4). For a more critical assessment, see Chomsky, N., Statement to the UNGA, Ibid., available online at <http://www.un.org/ga/president/63/interactive/protect/noam.pdf> (both accessed on 26 March 2012).

${ }^{10}$ For this view in the context of international humanitarian law, see Focarelli, C., "Common Article 1 of the 1949 Geneva Conventions: A Soap Bubble?", EJIL 21 (2010) 125-171.

${ }^{11}$ For scepticism based on state practice, see Focarelli, C., "The Responsibility to Protect Doctrine and Humanitarian Intervention: Too Many Ambiguities for a Working Doctrine", JCSL 13 (2008) 191-213.

${ }^{12}$ E.g. Meron, T., "Common Rights of Mankind in Gentili, Grotius and Suarez", AJIL 85 (1991) 110-116.
} 
However, as hinted earlier, the 'primary' obligations on states for the protection of human rights are unconnected to the consequences of their violation claimed by RtoP. States may (and indeed do) now have human rights obligations, but it does not follow that international law allows the measures envisioned by RtoP against their violation. Specific evidence (other than the mere existence of 'primary' human rights obligations) has to be provided, and it is on this ground that evidence is rather scarce at best.

\section{RtoP within the United Nations}

One might think that the RtoP may appropriately work (as opposed to just between states) in an institutional milieu, such as the United Nations, as a guide for the acts of the organisation and the legal evaluation of abuse of powers within it. It seems, for example, that the UN Security Council has endorsed RtoP, at least in part, in the recent Libyan case. ${ }^{13}$ However, this does not mean that the doctrine is a legal rule within the organisation. In fact, the Security Council remains at liberty to take up the doctrine and its decision to use it depends on the majorities of the day. Clear evidence for this is found in recent Draft Resolution S/2012/77 vetoed on 4 February 2012 by China and the Russian Federation in respect of Syria (with 13 votes in favour). ${ }^{14}$

Despite some proposals in legal doctrine to see the Council bound by RtoP, claiming in particular that the veto is to be regarded as irrelevant or illegal when the conditions of RtoP are met, practice suggests otherwise and no one has dared to hold that the recent Chinese and Russian vetoes are devoid of any effect and that the vetoed draft resolution is a perfectly valid resolution producing legal effects. ${ }^{15}$

A decision to resort to force by the other three permanent members favouring the draft resolution is an entirely different matter. It bears upon the admissibility of unilateral humanitarian intervention independent of the vetoed draft resolution, a course of action that finds no support in international practice and is likely to be met with strong resistance from the international community. Moreover, the irrelevance or illegality of the vetoy by permanent members in RtoP situations would have to be extended to the vote of all Security Council members since all of them contribute to the attainment of the majority under Article 27(3) UN Charter.

One should also ask whether a world in which in certain circumstances the veto is illegal is really a good idea. At present it nearly amounts to saying that while the veto of

\footnotetext{
${ }^{13}$ UNSC Resolution 1970, 26 February 2011 and Resolution 1973, 13 March 2011. For a brief comment, Focarelli, C., "Libya: a Turning Point for the Responsibility to Protect Doctrine?", e-International Relations, 6 April 2011, available online at <http://e-ir.info/2011/04/06/libya-a-turning-point-for-the-responsibility-to-protectdoctrine/> (accessed 26 March 2012). See also UNSC Resolution 1975 (2011), 30 March 2011, on Côte d'Ivoire.

${ }^{14}$ UNSC Draft Resolution S/2012/77, 4 February 2012, text and Security Council debate available online via <http://www.un.org/Depts/dhl/resguide/scact2012.htm>. UN Press Release available online at <http://un.org/News/Press/docs/2012/sc10536.doc.htm > (both accessed on 26 March 2012). It is worth pointing out that Draft Resolutions S/2012/77 expressly excluded any military action, noting that "nothing in this resolution authorizes measures under Article 42 of the Charter" (preamble).

${ }^{15}$ For the view that when RtoP applies the veto in the UN Security Council may amount to an abuse of rights and should be regarded as 'legally irrelevant', if not plainly illegal, see recently Peters, A., "The Responsibility to Protect: Spelling out the Hard Legal Consequences for the UN Security Council and its Members", in: Fastenrath, U., Geiger, R. and Khan, D. (eds.), From Bilateralism to Community Interest: Essays in Honour of Judge Bruno Simma, Oxford University Press, Oxford, 2011, pp. 297-325, 317 and 322. In the Preventing Genocide Report (Supra note 6) the veto power is retained (96), while recommending that an agreement can be made to remove it (106), which confirms that in the absence of such an agreement (by far the most likely occurrence) the veto power should be maintained. That the decision to cast a veto may in fact be more difficult in RtoP situations is a different matter which has no bearing on the legal relevance or validity of the veto. Countless unpleasant or unpopular factors influence the decision to cast a vetoy but few, if any, would dare to claim that they make the veto irrelevant or illegal for the sole sake of their unpleasantness or unpopularity.
} 
Western permanent members is always valid, since no doubt RtoP reflects their values, that of the Russian Federation and/or China (as the states usually contrary to RtoP) may sometimes be illegal. How long is such an asymmetry destined to last? Is this not to mean that the United Nations is to be dismantled?

The only proposition that makes sense in the present circumstances is that the UN Security Council is authorised to consider the conditions underlying RtoP as a 'threat to the peace' under Article 39 in order to take the measures envisaged in Chapter VII. ${ }^{16}$ But if one considers the Security Council practice of recent decades, starting with action against apartheid in South Rhodesia and South Africa during the Cold War and several other well-known instances after 1989, this is hardly a novelty for which the RtoP doctrine is necessary at all. One can concede that RtoP has contributed to 'legitimising', or even 'standardising', the notion that gross violations of human rights within a state may be considered by the Security Council as a 'threat to the peace' and triggers measures under Chapter VII. But this is only a permissive rule or a possible interpretation of Article 39, which is still subject to the majority and the veto power required under Article 27(3) UN Charter, certainly not a mandatory rule for the Council, let alone a signal that the veto is devoid of any effect when the RtoP applies.

\section{RtoP and the Current Global System}

Even assuming that states see in RtoP a legal norm having some importance in their relations within or outside international organisations, another key question still remains open. The RtoP doctrine generally fails to distinguish between individual states (i.e. states uti singuli) and states as a whole (i.e. states uti universi).

While the doctrine implies a weakening of individual states within a global states system, it does not question the global states system as such. True, it relies heavily on non-state actors, but as catalysing forces hopefully having an influence on states. However, the issue of globalisation does not so much concern the weakening of this or that state as the system as such. It is 'the' state, rather than this or that state, which is failing to deliver protection as a result of globalisation. No doubt the two planes overlap and the crisis of the global system is felt, first of all, within certain individual states, which may be former colonies (such as 'failed states'), developing countries or Western states (these, in particular, when facing macroeconomic factor crises, such as the latest global financial crisis).

It is also true that the crises of individual states, especially the most influential ones, shape and substantially contribute in undermining the entire global system. After all, it is still states (or, more accurately, certain states) that have pushed the system towards what has recently been critically called hyper-globalisation. ${ }^{17}$ But, whatever the reasons for crises in individual states, one should wonder how RtoP can work when the entire system of states on which it rests fails to work.

The signs of an increasing inability of the global system of states as a tool capable of working for the protection of people are hard to deny. ${ }^{18}$ People are more and more dissatisfied with governments of any kind. There is apparently no easy recipe, whatever the ruling party or

\footnotetext{
${ }^{16}$ See Conforti, B. and Focarelli, C., The Law and Practice of the United Nations, $4^{\text {th }}$ rev ed, Nijhoff Martinus Publishers, Leiden, 2010, 204-220.

${ }^{17}$ Rodrik, D., The Globalization Paradox: Why Global Markets, States, and Democracy Can't Coexist: Oxford University Press, Oxford, 2011, arguing for the preservation of states' centrality and diversity in a sustainable, "moderate" globalization to turn to in the future.

${ }^{18}$ The literature is enormous, ranging from those who argue that by now it is multinational corporations which "rule the world", such as, typically, Korten, D. C., When Corporations Rule the World, $2^{\text {nd }}$ ed., Kumarian Press and Berrett-Koeler Publisher, Sterling and San Francisco, 2001, to state-centrist sceptics, such as Drezner, D. W., All Politics is Global: Explaining International Regulatory Regimes Princeton University Press, Princeton and Oxford, 2007.
} 
class, for delivering what the state promises. It seems that the real problem is the state as the institutional structure rather than any government. The promise of the state to provide 'law and order' when religious wars were about to disrupt political loyalties in Europe, which was decisive for states to prevail over their competitors, ${ }^{19}$ as well as the twentieth-century pursuit of welfare policies and the global move to democracy, proves more and more difficult to be kept. International crimes are no longer sufficient as RtoP standards and mostly refer to the behaviour of states (failed or not) that are of little relevance to the disruption of the global system.

Heinous as they may be, the crimes committed in Darfur (despite their characterisation as 'crimes against humanity') have a far smaller impact on humanity, i.e. on the billions of people living on earth, suffering from the consequences of the global economic system. RtoP requires measures against other globally irresponsible acts (which might hopefully become international crimes in the future) such as white-collar crimes, state failure to prevent and/or punish private entities (including MNEs and their chief executives) for their misdeeds, state budget mismanagement and corrupt state officials, misappropriation of public funds, especially when substantially contributing to global financial crises with devastating effects on the most vulnerable.

States appear both unwilling and unable to meet such standards. They are even less able (let alone willing) to intervene against irresponsible states unless intervention makes them stronger. Nuclear weapons and 'mutual assured destruction' (MAD) have limited the possibility of war against foreign aggressors, thus significantly containing the power of the state to protect its own citizens in their perception. Apart from 'forgotten wars', the only wars apparently possible today are those fought in the name of the global community, i.e. those supported by the nuclear powers, thus warding off mutual destruction. Democracies have shaped states in such a way as to contain authority and empower individuals. ${ }^{20}$ Economic hyper-globalisation has limited the power of the state to protect the value of money, property, water, food, employment, etc. Economic calculation holds the scene and drives individuals towards a sauve qui peut strategy across the globe. The inevitable consequence of a powerless state is a 'migration' of most people towards what promises a better protection than that of the state.

It seems, paradoxically, that states are simply too costly to stay in the states system. States appear not to be able to survive without raising their debt to unmanageable levels, thus facing the risk of bankruptcy, once wars of conquest, slave trade, and colonialism are no longer possible, at least overtly, and unless the state sells itself (notably its essential services for the most vulnerable) to private businesses, thus strengthening the stronger and weakening the weaker.

States have always needed capital and resources to function. ${ }^{21}$ But taxation is no more viable beyond a certain (often too low) threshold, meeting with the opposition of the voters. Loans to states risk not being repaid. States are thus compelled to privatise public goods and services, which further weakens them. The state appears to be strangling itself by promising what it cannot afford. Or, to be more accurate, certain states (those which are confident in their ability to control private actors) push for 'less state' to weaken their rival states (which are supposed not to possess as much control over empowered private actors) in their competition to dominate the globe, or at least to prevent their competitors from doing so. Human rights require states that are able, in addition to willing, to protect them. But this is possible only in a global economic system, which places human rights, rather than power and profit, centre stage. This, in turn, is possible only in a system where states find themselves less compelled to any conduct whatsoever in order to survive and stay in the system.

\footnotetext{
${ }^{19}$ Spruyt, H., The Sovereign State and Its Competitors Princeton University Press, Princeton, 1994.

${ }^{20}$ Franck, T. M., The Empowered Self: Law and Society in the Age of Individualism, Oxford University Press, Oxford, 2001.

${ }^{21}$ Tilly, C., Coercion, Capital, and European States, A.D. 990-1992, Blackwell, Cambridge, 1990.
} 
The problem is political, not economic.

Global competition is simply a direct consequence of the global political competition between all (actual and potential) power centres, which aspire to control as many people as possible, since power is directly proportional to the number of people controlled.

How can a doctrine such as RtoP, grounded as it is in strong states and in a strong global states system really work in such an apparently self-strangling environment? How can the doctrine match its ambiguous need for both strong (controlling) states and weak (controllable) states? A sceptic would suggest that there is only one way to resolve the contradiction: RtoP will strengthen certain states (those currently stronger) and weaken certain others (those currently weaker). This is plausible. However, another possible trajectory, as discussed below, is that the entire global states system is replaced.

\section{Protection, Obedience, and Belief}

RtoP is premised, as already noted, on the notion that states exist for the ruled, not for the rulers. ${ }^{22}$ States are supposed to protect the people. In reverse, people expect protection from the state. It is basically on this basis that they accept obedience to the state. To make sense of this commonplace it is noteworthy that in any group, whether the state or a tribe, individual members unite because they cannot survive alone and need a powerful group to protect them. This is possible if the group is cohesive enough, but cohesion depends on authority and power of the group as a whole towards its individual members.

A state can ensure protection when it has the power to make itself obeyed by the transgressors. At a time when the prevailing catchwords are 'freedom' and 'rights' and words like 'duty' and 'responsibility' are a taboo-definitely the worst words a politician can utter before election - and when too few connect the freedoms and rights of someone to the duties of someone else, and vice versa, the state proves unable to meet the needs of most voters. It cannot deliver unlimited rights to all with duties for no one. And RtoP is indeed premised on such idea. It promises rights to the people, while imposing duties on state officials. But the point might be reached at which it is the irresponsibility of the people that invites irresponsible political leaders.

Democracy requires states to do what their citizens, or more accurately their majorities, desire. Unfortunately, people may want the state to behave contrary to the requirements of RtoP. So the doctrine erodes not only the state as an institution (uti singulus), but also democracy as a form of government, in the name of values apparently established by the 'international community as a whole'. Belief appears to be crucial in this regard. It is what most people believe that guides the process. If people believe that they have to enjoy rights and freedoms without being prepared to fulfil the correlative duties, then it is they who erode the state and, to the extent that the process spreads to the whole planet, as seems to be the case at present, the global system of states as such is undermined by the people themselves.

However, while in need of strong states, RtoP actually works to weaken states through the empowering of individuals. When the people within an 'irresponsible' state by RtoP standards feel that the state has become unable to protect them, according to their perception of protection, then they are prone to substitute the state for another entity, which here we can call $X$, that proves better than the state to provide the level and kind of protection expected. The issue of responsibility to protect then calls for an entity $X$, radically different from any state and from the system of states as a whole.

\footnotetext{
${ }^{22}$ Augustine of Hippo, De Civitate Dei contra Paganos, Book IV, Ch. 4, "Justice being taken away then, what are kingdoms but great robberies?"
} 


\section{RtoP in the Global System to Come}

If the erosion touches upon the entire system, rather than a particular state, the problem is about another system, not a different, better way to make the current system work. To inquire into 'another system' implies that RtoP is to be discarded altogether on the very ground of lack of protection since it proves itself unable to give states the ability to protect their people. One is thus led to define the 'next' global system before trying to figure out a doctrine that may perform the tasks of RtoP or attain its objectives in the new environment. What might the new global system look like? What needs to happen for it to replace the current system?

The replacement will occur when enough people on the planet are dissatisfied with 'the state' (meaning first their own state, then the state as such, and hence the states as a whole) compared to their expectations of protection. The more the state is unable to protect the people, the more people will incline towards Entity $X$ which will promise what the state is unable to deliver and (unlike the state) apparently keep its promise.

One of the key promises it needs to make in order to attract as many people as possible, and to obtain from them support and power, is to provide 'for free' what people expect from the state, typically, paying no taxes. This will appear to most people as a 'brilliant solution' because people want protection from the state (i.e. recognition of all 'their' individual rights for living as they please) without paying the price (i.e. without recognising that in this world rights, as anything else, are not unlimited, and they are possible for certain people at the cost of others, via correlative duties).

Entity $X$ has only to devise a system in which most people see the benefits but do not see the burdens and costs. It has to devise something which sounds extremely attractive to most people, so attractive (because of its ability to display individual empowerment without imposing duties) that participation is simply a pleasure, such as when a slave likes to be a slave and has no intention in being anything other than what he/she is.

Marketing strategies normally succeed in making people slaves of the products purchased, carefully and successfully avoiding the purchasers discovery of this. Purchasers are simply 'satisfied' with their choices and live in a wonderland where all their desires ostensibly become true. When awareness of the burdens and costs arises, then another communicative strategy simply follows, pointing to a different attractive pleasure. Unlike the self-conscious slave, the purchaser (i.e. he/she who has the power to purchase things and persons in the free market) believes that he/she is participating in a thrilling, self-empowering enterprise. The point is what most people believe, and are made to believe, not what actually occurs. Entity $X$ will succeed in doing exactly what the state proves no longer able to do: to make itself obeyed. And most people will be satisfied because Entity $X$ proves to be able to protect them apparently for nothing in return. There will be people who will suffer from power and abuse thereof by Entity $X$. But the losers will have no voice, as ever, because of the pervasive myth that Entity $X$ has successfully propagated.

What will Entity $X$ look like? We cannot know. Its design is in the mind of very few aspiring leaders capable of imagining an invisible world yet to come. Entity $X$ will do what all such entities have always done, including states: to make themselves obeyed. However, what will change is the mythic dimension surrounding obedience. The message will no longer be the one used by the state, such as nationalism or welfare, an 'old-fashioned' message now attractive only to a few nostalgic outsiders. The message will be different, but not the substance. What matters is what people believe. We are thus in the making of a new fairy tale about how we can live together. New fairy tale tellers are around the corner in fierce competition with one another to capture people's needs and dreams. There will be a period of time in which the most successful fairy tale will work because of the general enthusiasm and faith of most people.

Other people, different from current winners, will become the new winners within the new fairy tale and new losers will replace the current ones. 
Entity $X$ will presumably present itself as 'global', using the ongoing pro-global propaganda as its trump card. Everything will be different and human rights will mean quite different things than today. But most people will keep asking for protection, with no will to offer obedience unless forced to do so, selling themselves to the best purchaser in the market who will promise protection apparently for free.

\section{Conclusion}

Faced with the above futuristic scenario, we have to insist that the current global system of states, although often unsatisfactory and increasingly under strain, is worth supporting and struggling for together with RtoP. We still need states, but states that behave responsibly. And states will behave responsibly when their people as a whole, not only state officials, are responsible. We need people who believe in the state and make the best of it, first of all by taking on duties in favour of the most vulnerable. Better states will make better international law and better international law will force individual states to improve their behaviour. Other non-state 'sirens' promising better protection than the state (i.e. rights and freedoms for all and duties apparently for no one), selling the idea of going at last 'beyond' the constraints of the state, are designed to drive people in a land in which no one is legally protected and the stronger simply win because of their greater strength. This would mean a return to the jungle, but this time a global jungle with no escape. ${ }^{23}$

www.grojil.org

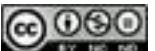

${ }^{23}$ For further analysis, see Focarelli, C., International Law as Social Construct: The Struggle for Global Justice, Oxford University Press, Oxford 2012, forthcoming, Chapter 8. 